\title{
Chaotic Behavior in Exchange Rate
}

\author{
Melike E. Bildirici ${ }^{1} \&$ Bahri Sonüstün ${ }^{2}$ \\ ${ }^{1}$ Department of Economics, Yildiz Technical University, Esenler/Istanbul, Turkey \\ ${ }^{2}$ Department of Economics, Institute of Social Sciences, Yildiz Technical University, Esenler/Istanbul, Turkey \\ Correspondence: Bahri Sonüstün, Department of Economics, Institute of Social Sciences, Yildiz Technical \\ University, Esenler/Istanbul, Turkey.
}

Received: October 18, 2018

doi:10.5430/ijfr.v10n1p17
Accepted: December 3, 2018

Online Published: December 16, 2018

URL: https://doi.org/10.5430/ijfr.v10n1p17

\begin{abstract}
In this paper, we aim to analyze the chaotic structure of the daily Euro/USD parity. The examined data covers the period of 01/01/2004 and 03/04/2018. In this context firstly, to determine chaotic behavior of daily Euro/USD rates, the BDS test was used. And following, the chaotic behavior was examined by Largest Lyapunov Exponents (LLE) and Henon Map methods. The results proved the existence of chaotic structure in the data.
\end{abstract}

Keywords: the BDS test, exchange rate returns, Lyapunov exponents chaos, Hennon map

\section{Introduction}

Social sciences, especially economics, are mostly interacted not only with the other branches of social sciences but also with the physical sciences such as mathematics, biology, physics, etc. The theoretical structure of the Classical economy is figured by Newtonian physics- These implications enabled the scientists to make linear analysis. In time, the generated linear models are not considered as sufficient to determine the real structure of the economy. Newtonian approach was seriously criticized by some the scientists because the estimations of it is not matching with real life and market experiences (Karaguler, 2000; Bildirici et. al. 2017; Torkamani, et. al., 2007; Wu and Zhang, 2007).

The critics, handled by the scientists, because of inadequacy in technical advancement and calculation technologies accordingly, it was not possible to make more complicated estimations and evaluations. However, by important developments in information and computer technologies in 1950s, it became possible to make more complicated researches. Through these technological developments, the nonlinear approach was utilized by most of the sciences especially in economics. Non-linear analysis provided the chance to economist and finance specialists to make more consistent forecasts which reflect the real market experiences, in their analysis.

Chaos, which represents the actual structures of financial time series, is accepted as one of the most significant developments in sciences. Lorenz (1960, 1962 and 1963) is accepted as the first scientist who introduce to chaos theory, asserted that small changes in decimals create huge differences in the results of atmospheric analysis. In the 19th century, Newtonian approach, based on linear pattern, claimed that almost everything is predictable while Maxwell (1980s) suggests the presence of unpredictability in his studies. Following, Li and Yorke (1975), May (1976) and Day $(1982,1983,1997)$ examined the chaos theory in economics.

Chaos theory is a part of complex systems, which comprises the non-linear interactions of many variables, run against the dominant paradigm. These approaches became a natural rival to the dominant paradigm. According to the chaos theory, most of the systems are quite sensitive to the initial conditions. The movements in the systems exponentially grow, but the paths are neither move further nor close to a specific point. That was identified as deterministic system acting randomly (Zhang, 2005).

Exchange rates which are considered as an important figure to determine power of the currency in international trade, show the real value of the national money in the global economy. Also, it offers about the analyzed countries' economic conditions that make possible to offer proper economy policy suggestions.

Before the 20th century, the foreign exchange (FX) rates are mentioned in the international trade among the countries. Export and import amounts were determinative variable for the FX rates till the second half of the 20th 
century. As we mentioned above, technological infrastructure improved after 1960s also enabled the international trade volume to increase.

After 1990s, by the financial capitalization, capital investments became more influential in international economy. The increasing volume and speed in money transfer correlated with technological improvements which give cause financial markets for being more complicated, are the other substantial factors in determination of FX rates. High mobility in capital, investing in the other currencies give the money markets high amount of transaction volume. And also, the pattern of the FX rates is affected by financial and economic variables. Output of the economies, interest rates, trade deficit/surplus and the other issues are important figures for the exchange rate and forecasting the FX rates became so important for economic agents (Plakandaras et al, 2018).

One of the other important factors that affect the behavior of the FX rates is the short/long term capital movements. This kind of fluctuations especially became important after the 1990s. Large interactions across the capital movements make impossible to analyze the time series by using traditional methods. Therefore, the chaos theory provides an acceptable and suitable point of view to examine the actual behavior of the series (Ou et al, 2010) because by using linear approach, it is not possible to provide sufficient information about the data's pattern. The presence of non-linear models provides an important advantage to analysts to forecast. However, financial data, due to high amount of variables, has huge fluctuations, shows irregular behaviors and that has unforecastable sudden movements which can be interpreted as chaotic.

In financial market and FX rates' characteristics, so many interferes cause to irregular moves on the data and this leads to chaotic behavior. Chaos theory addresses to constrained consistent performance, which is neither a point steadiness not periodic or quasi-periodic (Barkoulas and Travlos, 1998; Bhattacharya and Sensarma, 2006). This characteristic feature of the chaotic determination is expressed as 'sensitive dependence on beginning (initial) state' that means two points with alike initial condition possibly follow different trajectories (Bhattacharya and Sensarma, 2006). Lyapunov exponent is used to gauge the average deviation from starting point of the system.

This paper aims to determine chaotic and/or nonlinear behavior of FX rates. For this reason, firstly, the Brock, Dechert ve Scheinkman (BDS) test is used and following LLE and also the Henon Map are applied to determine the presence of chaos. In this structure, this paper consists of four sections. Accordingly, the literature review part of the study is placed in the second section. The data and econometric methodology is placed at the third section, econometric results is discussed in the fourth section while the last section forms the conclusion of the paper.

\section{Literature Review}

There are many papers about the chracteristics and the presence of chaos in the exchange rate data. Frank and Stengos (1988) and Scheindman and Lebaron (1989) found the proofs of the existence of chaos in markets. Aczel and Josephy (1991) measure the presence of chaos with correlation dimension. According to study, highly managed Singapore currency has smaller correlation dimension compared to European countries. Rubio et al. (1992) tested the deterministic chaos on daily Peseta-USD exchange rate and their findings show the presence of chaotic behavior in the series. Vassilicos et al. (1993) focused on USD/Mark, USD/Swiss Franc FX rates and New York Stock exchange data. Over 20,000 data is used and according to the analysis, no chaotic behavior is presented, but multifractal structure is detected. According to the paper, chaotic behavior can be seen at smaller samples but it cannot be observed at higher amount of data. Lux and Marchesi (2000) found that the presence of high amount of interactions between market agents caused to the chaotic behavior in the financial markets. Gilmore (2001) found contradictory signals about the chaotic pattern in the data. De Grauwe and Vansteenkiste (2001) mentioned that determining the chaotic structure of the data is almost impossible due to very limited ability of the appropriate tools to analyze the dynamics of chaos.

Das et. al. (2012) focused on Indian and Chinese FX rates against USD by applying Lyapunov exponent test and found the proofs of the chaotic structure in both fx rates. Dezhkam et. al. (2015) tested the chaotic behavior on daily Iran currency by BDS test, Hurst exponent, LLE and correlation dimension. The presence of non-linear structure and chaos are proved. Bildirici et al. (2017) focused on the fx rate data to search the existence of the chaotic structure in the series and found the chaotic dynamics by using Lyapunov exponent and Henon map. Lahmiri (2017) searched for the evidence of the chaotic structure in Moroccan exchange rates using Largest Lyapunov Exponent. The results found the presence of chaos on currency levels and for short and long term. At Diaz and Chen (2017) determined the chaotic behaviour in currency ETN returns and evidences of chaotic dynamics were found. Plakandaras et al.(2018) searched the chaotic behavior of the BRICS's currencies by Lyapunov exponent and correlation dimension tests and chaotic dynamics are presented in all series excluding South Africa. The short run prediction can be possible but long run forecasting will not be successful according to the paper. Franch (2018) proved the chaotic behavior for German 
Mark, Japanese Yen, Swiss Franc and Pound. Alves et al. (2018) focused on Dow Jones Index to determine the chaotic dynamics. It was determined that the chaotic dynamics are exist, but prediction performance deteriorates at sharp movements, Tiwari and Gupta (2018) focused, in G7 stock markets, to search the presence of chaos with using Lyapunov exponent. Strong chaotic behavior was determined for monthly data.

\section{Data and Econometric Methodology}

\subsection{Data}

At our research, we studied the nonlinearity and chaotic pattern at the $\mathrm{f} / \mathrm{x}$ rates data between the dates 05/01/2004 and 03/04/2018 covering the era of 2008 economic crisis. After the BDS (Brock, Dechert, Scheinkman, 1987) test for nonlinearity investigation, Lyapunov Exponents and Hennon Map are used to determine the existence of chaotic signals for the selected financial foreign exchange data. Data is downloaded from www.investing.com.

\subsection{Econometric Methodology}

\subsubsection{BDS Test}

For $\mathrm{n}$ dimension, the correlation integral is presumed as; $B_{n, \epsilon}=\frac{1}{K_{n}\left(K_{n}-1\right)} \sum_{n \leq p<k<K} \sum I\left(y_{t}^{n}, y_{p}^{n} ; \in\right)$ in which, $K_{n}=K-n+1$ and $\mathrm{I}($.$) is the indicator function and the result will be 1$ if $\left|y_{t-i}-y_{p-i}\right| \prec \in$ for $I=0,1, \ldots, n-1$ or else zero.

Hence, the united probability is calculated;

$$
\operatorname{Pr}\left(\left|y_{t}-y_{p}\right| \prec \in,\left|y_{t-1}-y_{p-1}\right| \prec \in, \ldots . .,\left|y_{t-n+1}-y_{p-n+1}\right| \prec \in\right)
$$

The BDS test is:

$$
B D S_{n, \epsilon}=\sqrt{K} \frac{B_{n, \epsilon}-B_{1, \epsilon}^{n}}{p_{n, \epsilon}} \text { in which } p_{n, \epsilon} \text { is the standart deviation of } \sqrt{K} B_{n, \epsilon}-B_{1, \epsilon}^{n}
$$

\subsubsection{Largest Lyapunov Exponent (LLE) Test}

Some methods were used to calculate the presence of chaos. LLE test is the most known and used one among all the methods. The chaos' main feature is dependency to the initial conditions. This exponent is used to measure the distance of two trails with different initial conditions. If the distance increases, then the degree of chaos increases and forecasting becomes much harder (Bildirici et.al:2017; Plakandaras et al, 2018). If the Largest exponent value is high, there is a high sensivity to initial state. Higher Largest exponent value means to higher exponential growth.

For calculating LLE, the vectors that have ' $n$ ' components are;

$$
Y_{i}=y\left(t_{i}\right), y\left(t_{i}+1\right) \ldots y\left(t_{i}+n\right)
$$

The vectors that which's distance is lower than the value of $\mathrm{p}$ is calculated as;

$$
p_{0}(n ; i, k)=\left\|Y_{i}^{n}-Y_{k}^{n}\right\| \leq p
$$

The term in below is calculated:

$$
d_{s}(n ; i, k)=\frac{\left\|Y_{1+s}^{n}-Y_{k+s}^{n}\right\|}{p_{0}(n: i, k)}
$$

The calculation of Lyapunov's largest exponent is as shown:

$$
L_{e}(n, s)=\sum_{i \neq j} \frac{\log d_{s}(n ; i, k)}{N(N-1)}
$$


If the result is positive and very near to zero it can be said that there is a weak chaos. Negative value tells us that no chaos is present in the series possible to predict. But the presence of positive exponent means to the presence of chaotic dynamics.

\section{Econometric Results}

\subsection{Descriptive Statistics and Unit Root Tests}

Daily Euro/USD rates $(d f x)$ are tested at first differences by a series of descriptive statistics and BDS test. The results in Table 1 show that there may be a chaotic structure in the analyzed period of daily FX rates.

Table 1. Descriptive statistics and the BDS test

\begin{tabular}{lcccccc} 
Series: & Mean & Med. & Std.Dev & Skewness & Kurtosis & JB* $^{*}$ \\
\hline$\Delta d f x_{t}$ & 1.000014 & 1.000072 & 0.006058 & 0.099978 & 5.164799 & 732.1883 \\
\multicolumn{1}{l}{ BDS Independence Test Results: } & & & & & \\
\hline$\Delta d f x_{t}$ & & & & & \\
Dimension & BDS Statistic & z-Statistic & $\underline{\mathrm{C}(\mathrm{m}, \mathrm{n})}$ & $\underline{\mathrm{C}(1, \mathrm{n}-(\mathrm{m}-1))}$ & $\frac{\mathrm{c}(1, \mathrm{n}-(\mathrm{m}-1))^{\wedge} \mathrm{k}}{2}$ \\
2 & 0.008756 & 6.545560 & 3489879. & 4866633. & 0.496570 \\
3 & 0.018993 & 8.934278 & 2545694. & 4863525. & 0.349816 \\
4 & 0.026299 & 10.39011 & 1881157. & 4860408. & 0.246381 \\
5 & 0.030393 & 11.52187 & 1405741. & 4857234. & 0.173485 \\
6 & 0.032667 & 12.84367 & 1067887. & 4855164. & 0.122294 \\
\hline
\end{tabular}

Notes: JB is the Jarque-Berra test.

According to the Kurtosis and Skewness results, heavy tails and leptokurtic distribution are presented in the series (Table 1). The outcomes at the table indicate that the analyzed data diverges from normal distribution. The BDS test showed it can be rejected the null hypothesis that the series are linear. The BDS results recommended that the Euro/USD rates for Turkish economy can be non-linear that makes the possibility of the chaotic and/or nonlinear behavior of the structure of exchange data higher. So, the results refer that it is possible to exist chaotic structure in the $d f x$ series.

\subsection{Henon Map and Lyapunov Results}

The Henon map is a repeated distinct-time dynamical system which shows the chaotic structure in two-dimensional space.

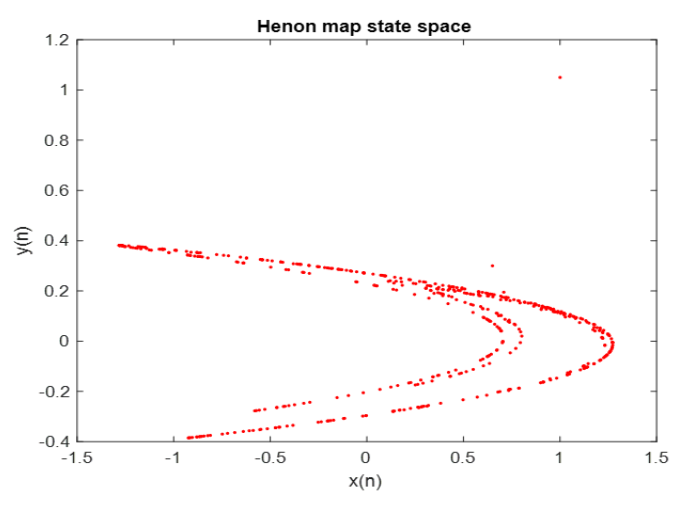

Figure 1. Henon map 
In Figure 1, it is seen that no points are escaping to infinity while they are repeating. This behavior proves the chaotic dynamics in the data.

In Table 2, for calculating LLE results, 1 to 10 dimensional structured vectors are utilized. According to results, positive LLE shows the chaotic pattern in data.

Table 2. The Largest Lyapunov exponent test outcomes

\begin{tabular}{lll}
\hline $\mathrm{D}=1$ & $\mathrm{D}=5$ & $\mathrm{D}=10$ \\
\hline 0.256 & 0.744 & 0.037 \\
\hline
\end{tabular}

FX rate presents the value of a currency compared to other currencies. New financial products, daily FX markets, investment opportunities and international trade are some factors that influence the FX rates. These factors generate extra ordinary movements on FX rates data. Trend, cycle, and seasonality issues of classic approach do not provide enough information to make forecast for analysts and researchers. Changes in FX system to floating system, data has strong non-linear and also chaotic features.

\section{Conclusion}

In this paper, searching the existence of chaos in the series is targeted. One of the most important features of the analyzed time period is inclusion of the 2008 economic crisis. For this reason, firstly, BDS test was applied to figure out the chaotic behavior of exchange rates. After BDS test, Largest Lyapunov exponent method was utilized to search the chaotic dynamics of the exchange rates. Following, positive Lyapunov exponent was calculated, chaotic dynamics in the data was proved. High level of irregular fluctuations causes to nonlinearity and also chaotic dynamics.

Chaotic tests are important for determining behavior of FX rate. The findings disclose that traditional linear methods are not suitable for analyzing data especially for financial time series data.

\section{References}

Aczel, A. D., \& Josephy, N. H. (1991). The Chaotic Behavior of Foreign Exchange Rates. The American Economist. https://doi.org/10.1177/056943459103500203

Alves, P. R. L., Duarte, L. G. S., \& Da Mota, L. A. C. P. (2018). Detecting Chaos and Predicting in Dow Jones Index. Chaos, Solitons and Fractals, 110, 232-238. https://doi.org/10.1016/j.chaos.2018.03.034

Barkoulas, J., \& Travlos, N. (1998). Chaos in an emerging capital market? The case of the Athens stock exchange. Applied Financial Economics, 8, 231-243. https://doi.org/10.1080/096031098332998

Bhattacharya, A., \& Sensarma, R. (2006). Do financial markets exhibit chaotic behaviour? Evidence from an emerging economy.

Bildirici, M., Sonustun, F. O., \& Sonustun, B. (2017). Chaotic Examination of Turkish Financial Market. AIP Conference Proceedings.

Brock, W. A., Dechert, W., \& Scheinkman, J. (1987). A test for independence based on the correlation dimension. Working paper, University of Winconsin at Madison, University of Houston, and University of Chicago.

Das, A., Das, P., \& Coban, G. (2012). Chaotic analysis of the foreign exchange rates during 2008 to 2009 recession. African Journal of Business Management, 6(15), 5226-5233.

Day, R. H. (1982). Irregular growth cycles. American Economic Review, 72, 406-414.

Day, R. H. (1983). The emergence of chaos from classica economic growth. Quarterly Journal of Economics, 98, 200-213. https://doi.org/10.2307/1885621

Day, R. H. (1997). Complex economic dynamics volume I: An introduction to dynamical systems and market mechanism. In Discrete Dynamics in Nature and Society (Vol. 1, pp. 177-178). MIT Press. https://doi.org/10.1155/S1026022697000186

De Grauwe, P., \& Vansteenkiste, I. (2001). Exchange rates and fundamentals A non-linear relationship? Center for Econ. Studies and Info Inst. for Econ. Res. Working Paper No. 577.

Dezhkam, A., Tash, S., Nabi, M., \& Khadijeh, D. (2015). Iran's Foreıgn Exchange Market: Investigation of Its 
Nonlinear Dynamics and Chaotic Behavior. International Journal of Academic Research, 95-103.

Diaz, J. F., \& Chen, J. H. (2017). Testing for Long-memory and Chaos in the Returns of Currency Exchange-traded Notes (ETN's). Journal of Applied Finance and Banking, 7, 15-37.

Franch, J. B. (2018). Exchange Rates Expectations and Chaotic Dynamics: A Replication Study. Economics-Ejournal, 34.

Frank, M., \& Stengos. T. (1988). Chaotic Dynamics in Economic Time-Series. Journal of Economic Surveys, 103-133.

Gilmore, C. G. (2001). An Examination of Nonlinear Dependence in Exchange rates, Using Recent Methods From Chaos Theory. Global Finance Journal, 139-151. https://doi.org/10.1016/S1044-0283(01)00018-7

Karaguler, T. (2000). Chaos theory and exchange-rate problem. International Joint Symposium on Bus. Admin. Gökçeada.

Lahmiri, S. (2017). On Fractality and Chaos in Moroccan Family Business Stock Returns and Volality. Physica A: Statistical Mechanics and Its Applications, 473, 29-39.

Li, T. Y., \& Yorke, J. A. (1975). Period Three Implies Chaos. Amer. Math. Monthly, 82, $985-992$. https://doi.org/10.1080/00029890.1975.11994008

Lux, T., \& Marchesi M. (2000). Volatility Clustering in Financial Markets: A Microsimulation of Interacting Agents. International Journal of Theoretical and Applied Finance, 3, 675-702. https://doi.org/10.1142/S0219024900000826

Lorenz, E. N. (1960). Maximum simplification of the dynamic equations. Tellus, 12, 243-254.

Lorenz, E. N. (1962). The statistical prediction of solutions of dynamic equations. Proc. Internat. Sympos. Numerical Weather Prediction, 629-635. Tokyo.

Lorenz, E. N. (1963). Deterministic non periodic flow. J. Atmosph. Sci., 20, 130-141.

May, R. M. (1976). Simple mathematical models with very complicated dynamics. Nature, $261,459-467$. https://doi.org/10.1038/261459a0

Ou, C. M., \& Lai, Y. C. (2010). Chaotic Behavior of Exchange Rate: Perspectives on Large Lyapunov Exponent of USD-TWD Time Series.

Plakandaras, V., Gupta, R., Gil-Alana, L. A., \& Wohar, M. E. (2018). Are BRICS Exchange Rates Chaotic. University of Pretoria Department of Economics Working Paper Series.

Rubio, O. B., Rodriguez, F. F., \& Rivero, S. S. (1992). Chaotic Behaviour in Exchange Rate Series: First Results for the Peseta-U.S. Dollar Case. Economic Letters, 207-211. https://doi.org/10.1016/0165-1765(92)90291-6

Scheinkman, J., \& Lebaron, B. (1989). Nonlinear Dynamics and Stock Returns. The Journal of Business, $311-337$. https://doi.org/10.1086/296465

Tiwari, A. K., \& Gupta, R. (2018). Chaos in G7 Stock Markets Using Over One Century of Data: A Note. Research in International Business and Finance. https://doi.org/10.1016/j.ribaf.2018.08.005

Torkamani, M. A., Mahmoodzadeh, S., Pourroostaei, S., \& Lucas, C. (2007). Chaos theory and application in foreign exchange rates vs. IRR (Iranian Rial), World Academy of Science, Engineering and Technology International Journal of Social, Behavioral, Educational, Economic, Business and Industrial Engineering, 1(6), 265-269.

Vassilicos, J. C., Demos, A., \& Tata, F. (1993). No Evidence of Chaos but Some Evidence of M ultifractals in the Foreign Exchange and the Stock Markets. Application of Fractals and Chaos, 249-265. https://doi.org/10.1007/978-3-642-78097-4_16

Wu, Y., \& Zhang, D. Z. (2007). Demand function and chaotic behaviour by interaction between customers and suppliers. Int. J. Production Economics, (107), 250-259.

Zhang, W. B. (2005). Discrete Dynamical Systems, Bifurcations and Chaos in Economics. 